MEDICAL ASPECTS OF AMATEUR BOXING

by

Dr. J. L. Blonstein (London)

Reprinted from Proceedings of the Royal Society of Medicine - July 1966

Amateur boxing is a healthy sport the popularity of which (there are about 60, 000 active senior amateurs and about 250,000 schoolboy boxers) discredits many of the arguments against it. It encourages physical fitness, and breeds confidence, discipline, clean living and sportsmanship. It permits, under supervision, the release of excessive energy which might otherwise be spent on anti-social activities, and thereby plays an active part in combating juvenile delinquency. Serious injuries are comparatively rare, and the accident rate compares very favourably with those of other sports.

In 4,350 contests held under the auspices of the London Amateur Boxing Association, 136 injuries were reported - about 3\%. There were 42 cuts in the region of the eye, 6 of the lips, 3 of the forehead, 2 of the ears, 3 of the mouth and 1 of the nose. There were 3 fractured metacarpals, 2 fractured noses, 60 knock-outs, 9 cases of amnesia without loss of consciousness, and 5 sprains of the thumb or fingers.

The incidence of boxing injuries compares very favourably with that of injuries sustained in various other sports. Thus, in a series of 6,057 consecutive sporting injuries compiled by Dr. Otto Johansen (1955), the number of injuries appeared in the frequency shown in Table 1.

Far more cases of concussion were reported from skiing, football, wrestling and gymnastics than from boxing.

A survey of sporting injuries in a group of 995 university students in Queensland University (Baker et al. 1964) showed that the most dangerous sports as measured by injury rate per player were as given in Table 2 .

The fatality rate in boxing also compares favourably with that from other sports. Thus, an analysis of sports deaths in Great Britain and the U.S.A is shown in Table 3. 
In 1962 in the United States two boxers died after professional fights, and two after amateur bouts. (Throughout the world there were 12 boxing fatalities). This compares with 43 killed in car racing, 32 in football, 11 in outboard racing, 11 in golf, 7 in cycle racing, 7 in horse racing, 6 in track and field, and 6 in baseball in the U.S. In fifteen years 430 young Americans have been killed playing American football (American Football Coaches Association).

Table 1

6,057 consecutive injuries occurring at various sports in Oslo (Johansen 1955)

$\begin{array}{lr}\text { Ski-ing } & 1,784 \\ \text { Football } & 1,320 \\ \text { Gymnastics } & 622 \\ \text { Bathing and swimming } & 523 \\ \text { Handball } & 393 \\ \text { Skating } & 363 \\ \text { Tobogganing } & 279 \\ \text { Hockey and ice-hockey } & 135 \\ \text { Wrestling } & 116 \\ \text { Boxing } & 100 \\ \text { Athletics } & 90 \\ \text { Cross-country running } & 57 \\ \text { Tennis } & 30 \\ \text { Other sports } & 245 \\ & \\ \text { Total } & 6,057\end{array}$

Table 2

Sports injuries in Queensland University Students in 1961

$\begin{array}{ll}\text { Rugby football } & 0.44 \\ \text { Soccer } & 0.3 \\ \text { Gymnastics } & 0.29 \\ \text { Hockey } & 0.25 \\ \text { Judo } & 0.21 \\ \text { Australian Rules football } & 0.17 \\ \text { Boxing } & 0.17 \\ \text { Basketball } & 0.15\end{array}$

Injury rate per person

0.44

. 3

0. 25

0. 21

0.17

0.15 
Deaths at various sports in Great Britain and U.S. A.

Sport

Professional boxing

Amateur boxing**

Horse racing

(National Hunt Rules)

Flat racing

Canoeing

(British Canoe Union)

Rock climbing

(Mountain Rescue Committee)

Mountaineering in U.S.A.

(Ferris 1963)

Motor cycle racing

Gliding

(British Gliding Association)

Cricket

Rugby football

Association football

Swimming, diving

under-water swimming
Years

1946-62

1946-62

1953-62

1954-62

Nov 1960-

Oct 1962

1961

1951-60

122

1958-62

1958-62

1962

1962

1962

1962 68

12

45

2

6

11

7

2,000
No. of deaths

5 in 55,200 contests

9

8 in 170,000 rides

2 in 200,000 mounts 
The commonest boxing injury is simple nose-bleeding. This can easily be stopped during rounds by sitting the boxer upright, pinching the nares and applying a cold sponge. If the bleeding persists after the bout, plugging with adrenaline gauze or adrenaline-soaked cotton wool usually stops it. The plugging should be removed after twelve hours. More severe bleeding may indicate obvious damage to the septum and this will need early removal to hospital, where the bones can be manipulated with Walsham's forceps before bleeding and oedema cause obstruction.

Other nasal injuries: A cartilage injury is relatively common and may cause considerable nasal obstruction; damage to the ethmoid or vomer is rare. Manipulations should be done within ten days. Often when oedema subsides manipulation is found to be unnecessary. Boxing can be resumed after two to three months. If manipulation is unsuccessful, a submucous resection will be necessary; this means the abandonment of boxing, as does remodelling of nasal contours.

Fractured nasal bones are rare; 2 cases in 4, 350 contests. Elevation by Walsham's forceps is indicated and boxing should be forbidden for three months.

Superficial head injuries: Abrasions and lacerations are common on the face and skull. Bleeding should be stopped by pressure; fibrin foam applied with pressure on a pad of gauze or cotton wool is usually successful in obstinate cases. Bathing of the wound with warm saline is followed by the application of cetrimide (1\%) and light dusting with sulphathiazole powder. Antibiotics should not be applied locally, as they may cause sensitivity reactions.

Lacerations should be sutured. The so-called 'cut-eye' is usually situated over the supraorbital ridge or in the upper eyelid. In the scalp, if the wound has gone right through the thickness of the skin, suturing is essential, coapting the whole of the cut surfaces. Elsewhere, if there is no contusion and no dead space in the depths, it can be closed by approximating the skin edges. Von Horff's clips are an easy and quick means of approximating the skin edges. Small dry wounds can be held together and sealed with plastic material, e.g. Nobecutane. The most suitable suture material is silk thread. Dumb-bell plaster strips applied at right angles to the wound are also useful. Boxing should be prohibited for at least four weeks. 
The common black eye hardly ever needs treatment, but cold applications limit the extravasation of blood. A haematoma of the auricle if seen early, requires aspiration and the injection of Hyalase, 1 to $2 \mathrm{ml}$. Otherwise, the clot must be evacuated, the wound plugged and allowed to granulate from the bottom.

Fracture of the skull and intracranial haemorrhages: These are very rare ( 7 cases in thirteen years). However, fractures of the jaw occur at the rate of about two a season. A boxer should be given first-aid treatment and if there is a dislocation present, this should be reduced first by pressing on the lower molar teeth, downwards and backwards, whilst moving the chin upwards; he should then be sent to a maxillofacial unit. Boxing should be forbidden for six months.

Fractures and sprains: The commonest fractures are of the first metacarpal, fractures of the shaft usually occuring within the proximal third of the bone. Any significant displacement or angulation should be corrected by manipulation under an anaesthetic, followed by immobilization for three to four weeks. This is followed by active movements; painless function is restored in six to eight weeks.

The Bennett type of fracture of the base of the first metacarpal involves a true dislocation of the first carpometacarpal joint. Reduction is carried out by skin, pulp or skeletal traction for three weeks, applied to the thumb in abduction, which is incorporated in a below-elbow plaster of paris cast. Immobilization is maintained for a further three weeks, followed by active movements. Boxing can be resumed after three months.

Fractures of the shafts of other metacarpal bones seldom require anything more than plaster of paris protection for a week or so. If there is angulation or shortening, due to overlap, manipulative correction should be undertaken and the wrist and metacarpals immobolized for three to four weeks. Boxing can be resumed after eight weeks.

The commonest joint to be damaged is the first metacarpophalangeal joint. There may be extensive damage to the capsule with possible rupture of a collateral ligament, or a chip of bone may be avulsed. Immobilzation in semiflexion for three weeks is essential, followed by active exercises, and operative repair may become necessary. Boxing may not be possible for six weeks. Sprains of the interphalangeal joints should be treated on similar lines. 
Concussion: This is caused by a direct blow to the lower jaw, by an accumulation of the effects of blows on the cranium or by the head striking the floor of the ring. Unconsciousness may also be caused by a blow on the carotid sinus, a blow over the heart and, rarely, by a blow to the solar plexus. In the latter case the boxer usually remains conscious throughout but there is a reflex temporary paralysis of his legs, which prevents him rising. No ill-effects following this blow have been observed. Most boxers regain consciousness by the count of ten and are able to walk to their corners unassisted. If consciousness has not been regained by the end of the count the boxer is allowed to recover on the floor of the ring. He should be supported in the almost prone position, making sure that there is a good airway. If there is any period of unconsciousness or any retrograde or post-traumatic amnesia, even without loss of consciousness, the boxer should be admitted to hospital for at least twenty-four hours for observation. There are about $1 \%$ of knock-outs in the course of a tournament. For a boxer to become dazed by a head blow more than once in a bout is unusual.

The electroencephalogram has been used in the detection and prevention of cerebral complications. The more severe the injury, the more severe and persistent is the electrical abnormality. There is a lack of correlation between the clinical and EEG findings. Comparable trauma in a young person produces more severe changes than in the older subject.

Chronic Effects of Head Injuries

Cerebral injuries: Post-traumatic epilepsy has not been encountered in amateur boxers in over thirty-five years. Head injuries in boxers are supposed to produce multiple petechial haeomorrhages but these have never been demonstrated. The so-called traumatic encephalopathy (punch-drunk syndrome) first described by Martland in 1928, has been seen only once in an amateur boxer - an army boxing instructor, who developed cerebellar atrophy. It is extremely rare in Negro boxers and occurs in the 'slugger' as opposed to the scientific boxer.

Before the 1930s when professional boxers boxed twenty rounds and more cases of traumatic encephalopathy occurred. There was diffuse cerebral atrophy similar to presenile dementia (Critchley 1927), and dilatation of the septum pellucidum was common (Maudsley \& Ferguson 1963). The symptoms were fatuous or euphoric dementia, with emotional lability and little insight. The speech and thought became progressively slower and the memory deteriorated. Efficiency and conduct fell away and there was irritability, truculence and depression with paranoid colouring; whilst 
there might also be tremor and dysarthria. The final picture was a mask-like face, slurred monotonous speech, slowness of movements, tremors, persistent dull headaches, postural dizziness, deafness, poor vision, alcoholic intolerance, unsteady gait, shakiness and seizures.

With shorter bouts and modern medical control, the punch-drunk.syndrome has not been seen during the last twenty years in professional boxers. Kaplan \& Browder (1954) found that when they attempted to correlate physical features and performance data of each boxer, with the EEG recording taken before and after the contest, there was no significant correlation except that statistical analysis suggested that those men who were lowest in ring rating had the greatest percentage of disorganized EEGs. They felt that the main purpose of the EEG examination in professional boxers lay in the detection of grossly disorganized or changing wave patterns. In the presence of such an abnormality they usually felt justified in regarding a man as unfit for further contests. There is general agreement that whereas the EEG is abnormal in the majority of cases of the punch-drunk syndrome, there are some in which the record may be surprisingly normal.

Alterations in the EEGs observed after boxing are not pathological (Beaussart et al. 1960). The changes are functional or physiological. EEG tracings are greatly disturbed after injury but the alterations do not persist after four minutes, even when there has been loss of consciousness for more than ten seconds. When evaluating the results of EEG examinations, account must be taken of the possibility of the existen of significant slow posterior waves in young boxers prior to the trauma $(48 \%)$; they must not be interpreted as a manifestation of recently acquired disturbances.

Extradural haematoma is an emergency and has been responsible for most of the boxing fatalities. The subdural haematoma may be acute or chronic but the acute is usually associated with severe skull and brain damage. The chronic subdural haematoma is very rare. The injury to the head may be a mild one and it is occasionally forgotten by the boxer. The patient's symptoms may last for months or even years. The patient's level of consciousness characteristically fluctuates and the lateralizing signs are often vague and may be ipsilateral to the lesion, because of the contrecoup effect. Confusion, with a post-concussional state, is common but in this condition there is often a psychoneurotic component and there are no abnormalities of the nervous system and no drowsiness.

\section{The Eye}

Detachment of the retina is relatively common in professional boxers and is often bilateral. Usually its onset is delayed. When it occurs 
immediately following a blow, the blow probably coincides with temporary obstruction of the venous outflow from the choroid, e.g. by holding the breath, so that the overlying retina is temporarily stretched at the moment of impact. Myopes are more vulnerable than others. Haemorrhage into the vitreous, disorganizing it locally, may produce a strand-like opacity, which may be anchored at one end to the retinal surfaces. Sudden movements of the eye may pull on the retina at the point of attachment and cause a tear and retinal detachment. This may occur months later. Most cases of blindness in boxers are due to retinal detachments. In these days of successful eye surgery by scleral plication plus diathermy, photocoagulation, the laser light (monochromatic) and cryotherapy (application of intense cold), the prognosis is much brighter.

Once the retina is detached at any point, its spontaneous reattachment is very rare, except in cases associated with intense retinal oedema. The detachments seen in younger people, of traumatic origin and especially the bilateral types, often remain for long periods confined to the lower and temporal part of the fundus. The media remain clear and useful central vision may be retained, with a good lower and temporal field.

Nasal Injuries

Boxers rarely go through their careers without a fractured nose. Deformity due to the fracture of the nasal bones and cartilages is of four types (Gerrie 1934, 1938). When the force strikes the nose near the glabella the bridge is depressed, the tip of the nose is rotated upwards and the saddle-shaped nose with conspicuous nostrils is produced. When the blow is sustained at the junction of bone and cartilage, the deformi is flattening of the bridge and broadening of the base. A blow still lower down fractures or dislocates the bony or cartilagenous part of the septum. The displaced sharp septal margin gives rise to an obvious ridge within the nostril. Lateral violence displaces the nasal ridge to the side and an S-shaped deformity results.

Remodelling of the nasal contours may demand a submucous resection as a preliminary stage. The second stage entails a bone graft from the iliac crest or tibia, or some inert substance such as polyvinyl (solid or sponge). Results are relatively satisfactory, both in gaining an airway and cosmetically.

The late case of fractured nasal bones, in which the boxer presents himself months or even years after the injury, requires elevation of the skin and soft tissues and refracturing of the bones before their alignment can be restored. 
Other chronic stigmata of the boxer are scars from lacerations over and around the eyes, cauliflower ears resulting from untreated haematomata, and recession of the knuckles.

The strict medical supervision applied by the rules of amateur boxing is unsurpassed in any sport and ensures that only fit boxers are allowed to box, that boys are not matched with opponents greatly exceeding them in experience, and that the bout is stopped if it appears necessary in the interests of the health of a boxer. Records are maintained of the types of injuries sustained and protection is afforded wherever this is possible, whilst detajled studies are made into the effects of the more latent type of injury. There are hazards in all sports, and the Amateur Boxing Association feel that boxing is a useful and justifiable sport provided it is strictly controlled medically.

\section{References}

Baker A. Baker B. and Williams M. (1964) Med. J. Aust. i, 398

Beaussart M. Miquet G. Gaudier B. and Guislain F. (1960) Presse med. 68, 913

Critchley M (1927) Brit. med. J. i, 357

Ferris B. G. (1963) New Engl. J. Med. 268, 430

Gerrie J.W. (1934) Canad. med. Ass. J. 30, 37, (1938) Canad. med. Ass. J. 39,433

Johansen O.(1955) Idrett og Skader (Sports and Injuries). Oslo

Kaplan H. A. and Browder J. (1954) J. Amer. med. Ass. 156, 1138

Martland H.S. (1928) J. Amer. med. Ass. 91, 1103

Maudsley C \& Ferguson F.R. (1963) Lancet ii, 795 